\title{
Focal paroxysmal kinesigenic choreoathetosis
}

\author{
GORDON PLANT
}

\begin{abstract}
From the Department of Neurological Surgery and Neurology, Addenbrooke's Hospital, Hills Road, Cambridge, UK
\end{abstract}

SUMMARY Three cases of paroxysmal kinesigenic choreoathetosis are described in whom unilateral attacks were focally induced, together with a case in whom bilateral attacks only occurred. Treatment with phenytoin was effective in all cases. The aspects of the literature relating to focal and generalised attacks in paroxysmal kinesigenic choreoathetosis are reviewed.

The term paroxysmal kinesigenic choreoathetosis (PKC) introduced by Kertesz, ${ }^{1}$ has become generally accepted to describe an easily recognisable disorder in which brief paroxysms are precipitated by sudden movement. The paroxysms themselves vary in character, and may be tonic, dystonic or choreoathetoid, but are always of less than two minutes' duration. The limbs may be involved bilaterally, and more or less simultaneously, often the trunk and face in addition, or the attacks may be focal involving the arm and leg unilaterally. Many patients have unilateral attacks which may occur on either side. Occasionally such attacks spread to the contralateral limbs, or co-exist with bilateral attacks.

In only a few cases has a relationship between focal. movement of the limbs and focal attacks been reported. No reports mention this phenomenon being sought with negative results, and it is therefore at least possible that it may be a more common feature of paroxysmal kinesigenic choreoathetosis than the literature suggests. Three cases of paroxysmal kinesigenic choreoathetosis are reported with unilateral attacks provoked by unilateral activity and, for comparison, a patient with exclusively bilateral attacks. The relevent aspects of the literature are then reviewed.

\section{Case reports}

\section{Case 1}

A 17-year-old right-handed schoolboy was referred for evaluation of attacks which had occurred since the age of

Address for reprint requests: Dr Gordon Plant, 37 Mill Road, Cambridge, CB1 2AB, UK.

Received 25 July 1982

Accepted 3 September 1982 six, provoked usually by standing from sitting. Mild attacks consisted of a brief interruption of movement a few seconds after rising to his feet, more severe attacks were more likely to occur if he was anxious and less likely after taking alcohol. Witnessed attacks were induced by asking him to run on the spot after standing still for at least one minute. The right wrist would flex, the elbow extend and forward movement occur at the shoulder. As the attack developed, the right leg extended, the foot plantar-flexed and inverted, together with grimacing and retraction of the right side of his mouth. Should he attempt to continue running violent movements of the right arm, resembling hemiballismus, would result. At the longest, attacks would last twenty seconds, there was never impairment of consciousness and no sensory or other aura preceded them. Whereas hopping on the right leg after standing still would precipitate a typical right-sided attack, hopping on the left leg would result in an attack involving the left arm only, often so mild that the patient was unaware of its occurrence, but similar to the early phase of a right-sided attack. The patient was, himself, entirely unaware that attacks involving the left limbs could occur until this demonstration. For both types of attack there was a refractory period of three to five minutes before a futher attack could be provoked. This was, however, quite independent on the two sides: a left-sided attack could be induced immediately following a right-sided attack and vice versa.

\section{Case 2}

A 21-year-old right-handed man presented with a seven year history of attacks affecting either the left or right limbs, attacks on the left being more severe. The circumstances under which attacks occurred were identical to case one. The attacks were preceded by a sensation of pins and needles in either thigh ascending in a second or two to involve the arm on the same side, which would then draw across his chest, the wrist flexed and the forearm pronated. He would grimace and his jaw deviate towards the side of the attack. In fifteen seconds it would be completed. Witnessed attacks were reliably induced by asking him to sit for ten minutes and then calling him to his feet, or, having stood still for a similar period, asking him to run on the spot. They more frequently involved the left limbs, but could 
occur on either side, this to an observable extent being determined by which foot he first put to the ground. Hopping, however, always provoked attacks unilaterally and, as with case one, there was a refractory period for subsequent ipsilateral but not contralateral attacks. It was not possible to provoke a bilateral attack, the patient, however, related one instance. He had been standing still on the edge of a platform several feet high. He stepped backwards and unexpectedly fell off the edge. He landed in a sitting position and, apparently using all four limbs simultaneously, leapt to his feet. A bilateral attack then followed.

\section{Case 3}

A 28-year-old left-handed salesman was referred with a thirteen year history of attacks of involuntary movements involving the right arm. There was a family history of sinistrality. He had a vivid recollection of his first attack which occurred as he crossed the finishing line of a hundred yard sprint. Subsequent attacks have all been provoked by sudden movements of his right leg. Most frequently this would occur in standing from a sitting position, but a sudden movement of the right leg, or even the right foot alone, whilst sitting might induce an attack. He had never been aware of a left-sided attack. Witnessed attacks were provoked by asking the patient to lie motionless for ten minutes, then leap to his feet and begin hopping on his right foot. After three or four hops a sensory aura, which he finds impossible to describe, would occur in his right foot and ascend the right side of his body in no more than two seconds. His right arm would then be drawn involuntarily towards his face and his head turn to the right. The right forearm was pronated and the arm flexed at the elbow and wrist. No involuntary movements of the right leg were observed. After five seconds the right arm relaxed. He reported that he would always be sure to keep a handkerchief in his right trouser pocket. When the aura occurred he just had time to take the handkerchief out of the pocket and would disguise the attack as an attempt to blow his nose. No attacks could be produced by asking him to hop on his left foot and on no occasion were involuntary movements of the left limbs observed.

\section{Case 4}

A 19-year-old electronics engineer was referred for evaluation of attacks which had occurred since the age of eleven. The attacks were exclusively induced by sudden movement, such as standing from a chair, walking from a standing position or breaking into a run from walking. He described an aura "as if being high on drugs", rather than the focal sensory disturbances reported in cases two and three above. Two seconds later he would feel "tightening" of muscles simultaneously in all four limbs and his face. In witnessed attacks his arms would move across his chest, flexed at the elbows and wrist, in the attitude of a praying mantis. He would grimace and his trunk flex. He never fell, but was unable to walk or speak during an attack although consciousness was preserved throughout. After several seconds in this posture two or three clonic movements of the upper limbs would occur and over a further second or two the attack fade. As with the previous cases attacks were more likely to occur in situations of anxiety. As many as $\mathbf{3 0}$ attacks might occur in a day, and the patient was aware of a refractory period of about five minutes following an attack. Frequent attacks were witnessed and although at times the left and at others the right arm seemed more severely involved (usually the left) all witnessed attacks were always bilateral. The patient himself had never been aware of a unilateral attack and no manoeuvre employed to induce an attack other than a bilateral one was successful.

The following remarks apply to all four cases reported above. In all cases general and neurological examination were normal and there was no past or family history of epilepsy, similar attacks, or other neurological disorder. In no case were attacks precipitated by startle, coffee, hyperventilation, or passive movements of the limbs. In all cases routine haematological and biochemical studies, including copper studies, serum magnesium and calcium, were normal. Resting electroencephalograms were considered within normal limits in all four cases, and in case one an EEG of reasonable quality was obtained during and immediately following an attack which showed no significant abnormality. All cases underwent slit-lamp examination for Kayser-Fleischer rings and none were seen. CT scans were carried out in cases three and four and were normal. In all cases treatment with phenytoin was instituted and completely abolished the attacks which have not recurred for up to eighteen months following the introduction of phenytoin. Videotaped recordings of all the patients' attacks were obtained.

\section{Discussion}

Gowers $^{2}$ is often quoted as providing the earliest account of movement induced dyskinesia. His two cases, however, differed in certain respects from the concept of paroxysmal kinesigenic choreoathetosis that has emerged in the past twenty years. His first case had an illness characterised by "general powerlessness" and attacks of generalised tonic spasm, with loss of consciousness, evoked by passive movements of the spine. It was when this disorder abated that he was left with "irregular fixation of the limbs without loss of consciousness" induced by movement. His second case suffered attacks which would do well for paroxysmal kinesigenic choreoathetosis in that the age of onset was eleven, they were brought on by movement after sitting still, and lasted for about a minute but we are told that she was confused following the attacks and that at a later date they occurred independently of movement.

The first clearly recognisable account of the disorder, by Pitha, ${ }^{3}$ has features of present relevance. His patient's attacks manifested as brief (ten second) tonic involuntary contractions of the limbs provoked by sudden movements of the limbs after a period of inactivity. At first the attacks had been bilateral but 
from the age of seventeen were predominantly unilateral. It was observed that movements of either lower limb resulted in an attack in the limbs on the same side of the body. Movements of both lower limbs provoked bilateral attacks. This applied to both active and passive movements of the limbs.

The table summarises the findings in 73 cases considered by the author to be examples of paroxysmal kinesigenic choreoathetosis that have been reported since 1938. ${ }^{13-25}$ Pitha's case, and the four cases above, are included. The clinical features, with regard to age of onset, duration and character of the paroxysms, response to anticonvulsants, and precipitating factors are in accord with the criteria proposed by Kertesz.' Excluded are examples of "symptomatic" paroxysmal dystonia where thyrotoxicosis, ${ }^{26}$ hypoparathyroidism, ${ }^{27}$ multiple sclerosis, ${ }^{28}$ the sequelae of head injury ${ }^{29}$ and a number of other disorders have manifested as involuntary spasms induced by movement. Also excluded are cases with convincing EEG abnormalities associated with attacks, such as the second case described by Perez-Borja et al ${ }^{13}$ which may constitute a different nosological entity. Examples of Familial Paroxysmal Dystonic Choreoathetosis of Mount and Reback ${ }^{30}$ are not included.

Although the majority of cases, $(69 \%)$ have at least some unilateral attacks hitherto in only five $e^{3-5722}$ has a relationship between focal activity and focal attacks been mentioned and in no case has an unsuccessful attempt to demonstrate this been reported. The author was consequently intrigued to find that in all three of the present cases with unilateral attacks focal induction was possible. The fact that the refractory period may be independent on the two sides for focal attacks has not previously been reported.

It was not possible to induce unilateral attacks in Case 4 by the manoeuvres employed in the other three patients. Although there is no record in the literature of success in inducing focal attacks in such patients neither, again, is there a previous account of a negative finding. Nevertheless the question arises that bilateral attacks may arise from abnormal activity in sub-systems of the basal ganglia concerned with postural changes involving all four limbs and the trunk, rather than movement of the contralateral limbs, and that it is not possible to divide such attacks into two "halves". Some support for this idea arises from the fact that in only a small proportion of cases $(16 \%)$ do unilateral and bilateral attacks coexist and in most of these, as in Pitha's case and Case 2 above, the attacks are largely of one type, the other occurring rarely.

A sensory aura may be seen in patients with any form of attack but they are invariably bilateral in bilateral attacks, or, as in Case 4 , not somatically referred.

As can be seen in the table, a positive family history has been reported in all varieties of attack but with least frequency in those limited to one side. This might indicate that this group contains a proportion of cases with acquired hemisphere lesions. One reason for attempting to induce attacks focally in such patients is that the demonstration that attacks may occur on either side excludes an acquired unilateral hemisphere lesion although cases such as that described by Falconer $e t a^{\beta 1}$ must be exceedingly rare.

A few authors have attempted to induce attacks by passive movements of the limbs with both positive $^{31219}$ and negative ${ }^{101316}$ results. Passive movements were ineffective in the four cases reported above. It would be of interest to know how commonly passive movements are an effective stimulus in this disorder, and it is hoped that a clearer picture will emerge if cases of paroxysmal dystonia are subjected to more intensive study than has been the case hitherto.

Most recent authors have considered paroxysmal kinesigenic choreoathetosis to be a disorder of basal ganglia function rather than a form of epilepsy arising in the cerebral cortex. The evidence for this arises from the character of the attacks, the lack of EEG abnormalities during and immediately following attacks (although interictal EEG abnormalities have occasionally been reported, particularly in Chinese cases), and the absence of impairment of conscious-

Table Clinical features of 73 cases of paroxysmal kinesigenic choreoathetosis

\begin{tabular}{|c|c|c|c|c|c|c|c|c|c|c|c|c|}
\hline \multirow[t]{2}{*}{ Laterality of attack } & \multirow{2}{*}{$\begin{array}{l}\text { Number of } \\
\text { cases }\end{array}$} & \multicolumn{3}{|c|}{ Focal provocation } & \multicolumn{3}{|c|}{ Passive movements } & \multicolumn{3}{|c|}{ Family history } & \multicolumn{2}{|c|}{ Sensory aura } \\
\hline & & Pos & Neg & $N S$ & Pos & Neg & $N S$ & Pos & Neg & $N S$ & Yes & No \\
\hline $\begin{array}{l}\text { Unilateral (one side only) } \\
\text { Unilateral (either side) } \\
\text { Unilateral and bilateral } \\
\text { Bilateral only } \\
\text { Not stated } \\
\text { Total }\end{array}$ & $\begin{array}{r}25 \\
12 \\
11 \\
22 \\
3 \\
73\end{array}$ & $\begin{array}{l}4 \\
3 \\
1 \\
0 \\
0\end{array}$ & $\begin{array}{l}0 \\
0 \\
0 \\
1 \\
0\end{array}$ & $\begin{array}{r}21 \\
9 \\
10 \\
21 \\
3\end{array}$ & $\begin{array}{l}2 \\
0 \\
1 \\
0 \\
0\end{array}$ & $\begin{array}{l}4 \\
0 \\
1 \\
2 \\
0\end{array}$ & $\begin{array}{r}19 \\
13 \\
9 \\
20 \\
3\end{array}$ & $\begin{array}{l}5 \\
6 \\
8 \\
8 \\
3\end{array}$ & $\begin{array}{r}19 \\
6 \\
2 \\
13 \\
0\end{array}$ & $\begin{array}{l}1 \\
0 \\
1 \\
1 \\
0\end{array}$ & $\begin{array}{r}8 \\
7 \\
10 \\
9 \\
1\end{array}$ & $\begin{array}{r}14 \\
5 \\
1 \\
13 \\
2\end{array}$ \\
\hline
\end{tabular}

Pos $=$ Positive.

Neg = Negative.

NS $=$ Not stated. 
ness. The response to anticonvulsants is a feature of many paroxysmal disorders of the nervous system, such as trigeminal neuralgia, and does not necessitate classification with the epilepsies. Reports that paroxysmal kinesigenic choreoathetosis may respond to levodopa, ${ }^{19}$ which probably does not have anticonvulsant properties, ${ }^{32}$ are also in support of a basal ganglia disorder, as is the occurrence of symptomatic paroxysmal kinesigenic choreoathetosis in conditions known to affect basal ganglia function. ${ }^{26}$ No definite pathological findings were demonstrated in the only case so far necropsied ' ${ }^{\prime}$ and the finding of brain stem atrophy in one case examined by CT scan ${ }^{24}$ has not been confirmed in cases 3 and 4 above. The occurrence of the involuntary movements following change in posture, sudden movements or even, in some cases a change in pace whilst walking, running or swimming is in agreement with the concept that the basal ganglia are concerned with the initiation of movement.

That focal dystonia may be seen in other disorders in which dystonia occurs is well established,$^{33}$ and the focal manifestations of paroxysmal kinesigenic choreoathetosis emphasised in this article do not argue against a basal ganglia origin for the disorder.

I am grateful to Dr MFT Yealland and Dr IMS Wilkinson for permitting me to report the cases.

\section{References}

1 Kertesz A. Paroxysmal kinesigenic choreoathetosis. Neurology (Minneap) 1967;17:680-90.

2 Gowers WR. Epilepsy and other chronic convulsive diseases (Reprint of 1885 edition). New York: Dover, 1964:75-6.

${ }^{3}$ Pitha V. Epilepsie réflexe. Rev Neurol (Paris) 1927; 38:178-81.

4 Smith LA, Heersema PH. Periodic dystonia. Proc Mayo Clin 1941;16:842-6.

5 Michaux L, Granier M. Epilepsie Bravais-Jacksonian réflexe. Ann Méd Psychol 1945;103:172-7.

- Pryles CV, Livingston S, Ford FR. Familial paroxysmal choreoathetosis of Mount and Reback. Paediatrics 1952;9:44-7.

7 Lishman WA, Symonds CP, Whitty CWM, Willison RG. Seizures induced by movement. Brain 1962;85:93-108.

8 Lance JW. Sporadic and familial varieties of tonic seizures. J Neurol Neurosurg Psychiatry 1963;26:51-9.

9 Williams J, Stevens H. Familial paroxysmal choreoathetosis. Paediatrics 1963;31:656-9.

${ }^{10}$ Whitty CWM, Lishman WA, Fitzgibbon JP. Seizures induced by movement: a form of reflex epilepsy. Lancet 1964;i:1403-6.
"Hudgins RL, Corbin KB. An uncommon seizure disorder: familial paroxysmal choreoathetosis. Brain 1966;89:199-205.

12 Stevens H. Paroxysmal choreoathetosis: a form of reflex epilepsy. Arch Neurol 1966;14:415-20.

13 Perez-Borja C, Tassinari AC, Swanson AG. Paroxysmal choreoathetosis and seizures induced by movement (reflex epilepsy). Epilepsia 1967;8:260-70.

14 De Bolt WL. Movement epilepsy. Bull Los Angeles Neurol Soc 1967;32:1-5.

15 Fukuyama Y, Okado R. Hereditary kinesthetic reflex epilepsy. Proc Aus Assoc Neurol 1968;5:583-7.

${ }^{16}$ Kato M, Arachi S. Paroxysmal kinesigenic choreoathetosis. Report of a case relieved by carbamazepine. Arch Neurol 1969;20:508-13.

17 Burger LJ, Lopez RI, Elliot FA. Tonic seizures induced by movement. Neurology (Minneap) 1972;22:656-9.

18 Jung S, Chen K, Brody J. Paroxysmal choreoathetosis: report of Chinese cases. Neurology (Minneap) 1973; 23:749-55.

19 Loong SC, Ong YY. Paroxysmal kinesigenic choreoathetosis: report of a case relieved by L-Dopa. J Neurol Neurosurg Psychiatry 1973;36:921-4.

20 Vertucci P, Pascotto A, Volpe E. Coreo-atetosi parossitica. Acta Neurol (Napoli) 1977;32:293-7.

21 Waller DA. Paroxysmal kinesigenic choreoathetosis or hysteria? Am J Psychiat 1977;134:1439-40.

22 Goodenough DJ, Fariello RG, Annis BL, Ruggero G, Chun RWM. Familial and acquired paroxysmal dyskinesias. Arch Neurol 1978;35:827-31.

${ }^{23}$ Reitter B, Weisser J. Paroxysmal familiare choreoathetose. Mschr Kinderheilk 1978;126:405-7.

24 Watson RT, Scott WR. Paroxysmal choreoathetosis and brain stem atrophy. Arch Neurol 1979;36:522.

25 Kinast M, Erenberg G, Rothner D. Paroxysmal choreoathetosis: report of five cases and review of the literature. Paediatrics 1980;65:74-7.

${ }^{26}$ Fishbeck KH, Layzer RB. Paroxysmal choreoathetosis associated with thyrotoxicosis. Ann Neurol 1976;6: 453-4.

27 Simpson JA. The neurological manifestations of idiopathic hypoparathyroidism. Brain 1952;75:76-90.

28 Matthews WB. Tonic seizures in disseminated sclerosis. Brain 1958;81:193-206.

29 Robin JJ. Paroxysmal choreoathetosis following head injury. Ann Neurol 1977;2:447-8.

30 Mount LA, Reback S. Familial paroxysmal choreoathetosis. Arch Neurol Psychiat 1940;44:841-7.

${ }^{31}$ Falconer MA, Driver MV, Serafitinides EA. Seizures induced by movement: report of a case relieved by operation. J Neurol Neurosurg Psychiatry 1963;26: 300-7.

32 McPherson A. Convulsive seizures and electroencephalogram changes in three patients during levodopa therapy. Neurology (Minneap) 1970;20:41-5.

${ }^{33}$ Marsden CD. Dystonia: the spectrum of the disease. Res Publ Assoc Res Nerv Ment Dis 1976;55:351-70. 